\title{
DISCURSO E EXPRESSÃO DE COMPETÊNCIA AXIOLÓGICA EM LIVROS DIDÁTICOS DE LÍNGUA PORTUGUESA
}

Wander Emediato*

\begin{abstract}
Resumo: Este artigo procura explicar, nos manuais de Língua Portuguesa, a presença de estratégias didáticas voltadas para o desenvolvimento da competência axiológica-atitudinal, ou seja, dos aspectos afetivos e subjetivos. Trata-se de um estudo que, tendo por base a abordagem semiolinguística do discurso didático, toma como categorias de análise a Tematização e a Problematização conforme se verificam nesses livros didáticos..

Palavras-chave: discurso; livro didático; competência enciclopédica; competência procedural; competência axiológica-atitudinal.
\end{abstract}

\section{INTRODUÇÃO}

De modo geral, os processos de ensino/aprendizagem, bem como os resultados adquiridos através deles, são prioritariamente estudados e investigados em seus aspectos cognitivos e intelectuais. Assim, busca-se compreender melhor quais modelos de ensino ou de ações educativas poderiam provocar os melhores resultados em termos de assimilação de conteúdos e desenvolvimento de habilidades e competências. Por exemplo, as atividades de pré-programação didática, como os parâmetros curriculares nacionais, a construção de currículos e grades curriculares, em diferentes níveis de ensino, bem como os programas de disciplinas que visam ao desenvolvimento das ementas previstas são, de modo bem geral, descritivos de conteúdos, itens de conhecimentos, históricos de

\footnotetext{
* Professor da Faculdade de Letras da Universidade Federal de Minas Gerais, Belo Horizonte, MG, Brasil. Doutor em Ciências da Linguagem. Email: <wemediato@hotmail.com>.
} 
teorias, sumários de correntes teóricas ou de categorias e conceitos relacionados à disciplina. Em resumo, os saberes da programação didática são aqueles originados da pesquisa científica, ou saberes científicos (savoirs savants). A atividade de didatização opera certamente, como ressalta Galatanu (1996), uma série de transformações nesses saberes savants, operações de seleção, de organização, de reformulação em função dos públicos visados, dos objetivos nacionais, institucionais e pedagógicos, da dimensão sociocultural e espacial do ensino.

A didatização dos saberes savants, de modo geral, tem em vista objetivos de ensino centrados mais especificamente no desenvolvimento da competência enciclopédica (aquisição de conhecimentos) e da competência procedural (aquisição de habilidades, como escrever, falar uma língua estrangeira, somar, multiplicar etc.). Fazer-saber e fazersaber-fazer constituem, portanto, as visadas mais visíveis da comunicação didática e da didatização. No entanto, a experiência escolar não se limita atualmente, nem nunca se limitou no passado da tradição escolar, ao desenvolvimento das competências enciclopédica e procedural. A experiência escolar é também, e sempre foi, um trabalho de subjetivação, embora esse aspecto não concorra, nem de longe, com os anteriores nas operações de pré-programação didática. Jean-Yves Rochex (1998, p. 193), da equipe ESCOL da Universidade de Paris VIII, refletindo sobre esse mesmo problema, argumenta:

Se é bastante admitido atualmente, nos meios e no discurso da pesquisa em educação, da formação ou da prescrição pedagógicas - mas sem dúvida mais dificilmente nas práticas efetivas -, que a formação e a experiência escolar não podem ser pensadas apenas em termos de transmissão e de recepção de saberes, de conhecimentos e de competências mas também em termos de desenvolvimento, tal problemática diz respeito essencialmente ao desenvolvimento intelectual e cognitivo, e muito raramente ao desenvolvimento e à transformação de si sobre o registro afetivo e subjetivo. (Tradução nossa)

Se, por um lado, a reflexão sobre os processos de aquisição de conhecimento e de desenvolvimento de habilidades parecem orientar as práticas de didatização e os objetivos escolares, não é difícil notar, por outro lado, a presença marcante dos objetivos de subjetivação já nos textos oficiais de educação no Brasil. Na LDB - Lei 9.394/96 - 
(BRASIL, 1996), podemos encontrá-los, por exemplo, no artigo 35, em seus incisos II e III. De acordo com a Lei, são objetivos do ensino médio, entre outros:

II - A preparação básica para o trabalho e a cidadania do educando, para continuar aprendendo, de modo a ser capaz de se adaptar com flexibilidade a novas condições de ocupação ou aperfeiçoamento posteriores;

III - O aprimoramento do educando como pessoa humana, incluindo a formação ética e o desenvolvimento da autonomia intelectual e do pensamento crítico; [...]

Com efeito, o desenvolvimento de uma terceira competência, que chamarei aqui de competência axiológica-atitudinal, está relacionado, essencialmente, ao que se tem designado de espirito de cidadania e de espirito crítico. Esses dois tipos de espiritos, pela própria denominação corrente, designam um estado intrinsecamente subjetivo a ser desenvolvido nos alunos, uma competência bem diferente das duas anteriores aqui mencionadas, já que não caberia designá-las como espírito enciclopédico ou espirito procedural. O saber e o fazer não parecem constituir, no discurso didático, atitudes do espírito. Parecem ocupar um lugar mais físico (o cérebro) e mais exterior (instrumento).

O parecer da Câmara de Educação Básica, da conselheira Guiomar Namo de Mello - parecer CEB 15/98 - (BRASIL, 1998), ressalta que as diretrizes da educação básica que a Constituição e a LDB buscam implementar se situam em torno de três "consignas": sensibilidade, igualdade e identidade. Vale resgatar aqui os aspectos mencionados no parecer sobre a estética da sensibilidade:

Como expressão do tempo contemporâneo, a estética da sensibilidade vem substituir a da repetição e padronização, hegemônica na era das revoluções industriais. Ela estimula a criatividade, o espírito inventivo, a curiosidade pelo inusitado, a afetividade, para facilitar a constituição de identidades capazes de suportar a inquietação, conviver com o incerto, o imprevisível e o diferente. (BRASIL, 1998, p. 22)

Esses elementos presentes nos documentos oficiais ressaltam claramente o papel da subjetivação nos processos de ensino/aprendizagem, o que nos impõe uma reflexão mais sistemática 


\section{8}

sobre o lugar que ela ocupa nas estratégias de ensino e na própria programação didática e metodológica.

Nosso objetivo será, justamente, o de levantar algumas questões sobre o lugar que ocupa o desenvolvimento da competência axiológicaatitudinal, ou seja, dos aspectos afetivos e subjetivos, na programação didática e, mais especificamente, nos roteiros e atividades presentes em livros didáticos de língua portuguesa. Nosso interesse tem sido o de investigar os modos de subjetivação atualizados nesses livros para compreender melhor a que eles podem ser relacionados dentro de uma dinâmica de comunicação didática.

Parte do dispositivo da comunicação didática, o manual (ou livro didático) é ao mesmo tempo um suporte de atividades diretamente relacionadas à disciplina ensinada e um suporte de saberes que fazem referência ao próprio imaginário da formação escolar. A maior parte dos saberes se orienta para a formação de habilidades (competência procedural), outros para a assimilação de conteúdos (competência enciclopédica), mas outros se orientam para a formação de condutas e atitudes ideais (competência axiológica-atitudinal). O objetivo dessas estratégias didáticas está voltado para a formação de certos valores e condutas no aluno. Para analisar essas estratégias de ensino, vamos partir de uma reflexão específica da semiolinguística sobre a estruturação de saberes e de papéis e aplicá-los à situação escolar, buscando colocar em evidência a relação existente entre as características de certas atividades didáticas e a atribuição de propriedades identitárias aos alunos (saberes de crenças, saberes de conhecimentos, condutas) visando à sua transformação, além de atribuir também certos papéis ao enunciador didático.

Sabemos que grande parte das estratégias de ensino-aprendizagem resulta dos pressupostos que os atores sociais fazem uns dos outros dentro da situação de comunicação escolar. Isso ocorre, de fato, em qualquer troca comunicativa. É sobretudo relevante considerar, nesse processo, o papel das representações profissionais dos agentes educativos (professores, pedagogos, escritores de manuais de ensino) sobre suas produções discursivas (planos de aula, avaliações, manuais didáticos, parâmetros curriculares). Certas configurações presentes em manuais didáticos constituem um objeto importante de investigação, pois ali se encontram as escolhas feitas por educadores para atender a objetivos diversos da ação escolar, entre as quais ressaltamos: 
a) escolha de tópicos de ensino;

b) escolha de objetivos de aprendizagem;

c) escolha de atividades que, supostamente, desenvolveriam os objetivos almejados;

d) escolha de formas de atividades (tipo de perguntas, tipo de textos, tipo de exercícios, temas, etc.).

Certas atividades, por exemplo, parecem orientar a reflexão do aluno para respostas ideais (desejabilidade social), podendo ter, como consequência, impacto negativo no desenvolvimento de seu pensamento crítico. Nesse sentido, o trabalho de subjetivação estaria atendendo mais a representações que agentes de educação possuem sobre um imaginário de condutas sociais conformes e não ao que se poderia esperar de um trabalho de desenvolvimento do espírito crítico (considerando que um espírito crítico não é necessariamente um espírito conforme).

Buscando tão somente apresentar alguns elementos de análise para a nossa reflexão sobre a comunicação didática em seu trabalho de subjetivação, buscamos descrever o funcionamento do seu quadro enunciativo para, em seguida, refletir sobre os problemas que, no nosso entendimento, certas estratégias trariam para esse trabalho de subjetivação. Antes, apresentaremos alguns elementos de análise semiolinguística.

\section{ELEMENTOS DE ANÁLISE SEMIOLINGUÍSTICA DO DISCURSO}

Para Charaudeau (2001), a estruturação de um ato de linguagem comporta dois espaços, um espaço externo, relativo ao fazer social, e um espaço interno, espaço do dizer. No espaço externo, os parceiros do jogo comunicativo assumem papéis sociais (professor/aluno). No espaço interno, os protagonistas da encenação discursiva assumem papéis discursivos. É importante também apresentar, para uma melhor compreensão desse modelo de análise, o papel que assume a dimensão social em sua descrição e em sua interpretação. Entendemos que há dois lugares sociais 
do discurso: o lugar dos posicionamentos e o lugar dos condicionamentos comunicativos e enunciativos.

O lugar social dos posicionamentos é um lugar axiologizado e remete a uma problemática da representação, através do discurso, de sistemas de valores. O lugar de situação é um lugar condicionado pela experiência comunicacional dos agentes e remete a uma problemática da influência e da regulação, espaço onde os interactantes devem reconhecer os parâmetros e princípios de conformidade às diferentes situações de comunicação e seus formatos, scripts, roteiros e papéis (sociais e discursivos). Nesse lugar se definem a finalidade da troca, a identidade (psicossocial e discursiva) de comunicantes e enunciadores, o quadro de tematização e o dispositivo (circunstâncias físicas e materiais da situação de comunicação ou do gênero).

Esses dois lugares não são excludentes, mas podem ser objeto de uma investigação específica, a critério do analista. A análise pode se concentrar, por exemplo, na identificação de valores sedimentados pela tradição escolar, portanto estruturado e estruturante. Por outro lado, a investigação pode se concentrar na descrição das práticas comunicativas escolares, suas formas de interação, papéis assumidos pelos parceiros, desenvolvimento de finalidades, regularidades enunciativas etc. Em Emediato (2006), por exemplo, buscamos descrever as atitudes enunciativas regulares de professores e alunos em sala de aula, os tipos de atos locutivos mais recorrentes e suas modalidades, baseando-nos na hipótese de que a relação entre os dois era bastante regulada pela situação institucional e pelas representações dos agentes de educação sobre os papéis de cada um.

A descrição empírica dos fatos de linguagem, nessa perspectiva, busca ainda considerar três espaços de palavra que se complementam: os espaços de locução (como abordar o outro), da relação (coconstrução identitária) e da tematização (pertinência dos universos temáticos). O problema da subjetividade é também central. Uma teoria dos sujeitos vem complementar a análise do fenômeno, propondo quatro entidades diferentes, 2 externas (parceiros sociais) e duas internas (protagonistas discursivos):

a) Um sujeito comunicante, que detém a iniciativa do processo de produção.

EMEDIATO - Discurso e expressão de competência axiológica... 
b) Um sujeito interpretante, que detém a iniciativa do processo de interpretação.

c) Um sujeito enunciador, posto em cena pelo sujeito comunicante buscando adequação e conformidade com as expectativas do ato de linguagem e da situação de comunicação na qual ele se encontra em termos de seus papéis conformes, seus pontos de vista (não necessariamente assumidos pelo sujeito comunicante), as imagens de si ou as representações sociodiscursivas enunciadas (como no caso de metaenunciadores ou voz terceira - tiers);

d) Um sujeito destinatário, imaginado pelo sujeito comunicante como uma idealização mais ou menos conforme às propriedades da relação contratual que se busca estabelecer e que não corresponde necessariamente à realidade do sujeito interpretante.

Os sujeitos comunicante e interpretante pertencem ao circuito externo - espaço do fazer social -, assumem papéis sociais (professor, aluno) e são seres empíricos psicossociais, ou seja, correspondem a representações históricas circulantes no espaço social sobre o que são os papéis de professor e de aluno; já os sujeitos enunciador e destinatário pertencem ao circuito interno - espaço do dizer -, e assumem papéis discursivos, enunciativos e enuncivos, ou seja, são seres de palavra e correspondem a encenações discursivas ou atitudes. Esses elementos de base serão suficientes para nosso propósito nesta comunicação.

\section{ELEMENTOS DE ANÁLISE}

De início, podemos perceber que é sobretudo através das estratégias de tematização e de problematização que se articula, nos manuais, a formação de uma competência axiológica-atitudinal, e que elas estão intimamente associadas às propriedades da construção de um quadro enunciativo para o qual atuam fortemente as representações do agente de educação - o sujeito comunicante - sobre o sujeito destinatário (aluno imaginado). O trabalho de subjetivação coloca em cena diferentes tipos de enunciadores. Antes de apresentar a descrição do quadro enunciativo, 
vale ressaltar que os saberes que são enunciados em um discurso didático, como é o caso do livro didático, possuem os seguintes traços:

a) supõem um destinatário-alvo contendo propriedades cognitivas e afetivo-atitudinais; essas propriedades supostas no destinatário se tornam premissas da pré-programação didática;

b) propõem modelos de atitudes que, supostamente, seriam reconhecidos pelos aprendizes a partir dos modelos de reflexão inseridos nas atividades, como no caso da tematização e da problematização;

c) estimulam, assim, estados de adesão a enunciados sobre o mundo (crenças) a partir de uma suposta partilha dessas crenças.

Em razão desse estímulo sistemático a estados de adesão, a comunicação didática simula uma troca dialógica sem a necessária confrontação de representações dos aprendizes com o sistema de saberes proposto pelos programas. Se, de um lado, sempre foi papel assumido pela escola a formação de condutas sociais conformes, de outro lado, em se tratando de um objetivo mais moderno, como o de desenvolver nos alunos um pensamento crítico, a eficácia de certas estratégias não nos parece tão evidente.

\subsection{Análise da 'tematização' no livro didático}

Há diversos tipos de livros didáticos e, por isso, não temos o objetivo aqui de generalizar os fatos que iremos apresentar, pois eles dizem respeito a um livro didático dirigido à $7^{\mathrm{a}}$ série, cujo nome não nos interessa relatar neste ensaio. Os fatos que serão discutidos são, na verdade, bem comuns e podem ser encontrados facilmente em outros manuais, não constituindo, porém, uma característica necessariamente predominante.

Através da análise desse manual pudemos observar, em primeiro lugar, que ele buscou selecionar temas que supostamente se aproximariam do imaginário experiencial dos alunos, o que não é incomum em livros didáticos. Na elaboração da grade temática pudemos distinguir quatro tipos de temas de acordo com sua recorrência:

- Tema 1: namoro, solidão, medo, adolescência, aparência. 
- Tema 2: política, poluição, classes sociais, corrupção, consumismo, modernidade.

- Tema 3: Solidariedade, Humanidade, Liberdade, Velhice x Juventude, Morte.

- Tema 4: língua, a arte de falar, a arte de escrever.

De início, pode-se identificar, para cada um desses grupos, a proposição de um contrato de comunicação diferente, pois os enunciadores parecem mudar de acordo com o universo temático selecionado, assumindo diferentes papéis e construindo, por sua vez, diferentes imagens identitárias do destinatário. Nos textos presentes no $1^{\mathrm{o}}$ grupo, por exemplo, o enunciador didático assume o papel de um psicólogo-terapeuta em relação clínica com os alunos, que assumem, como destinatários, o papel de pacientes. Os temas abordados são considerados recorrentes e pertinentes para os alunos nessa fase de suas vidas. $O$ enunciador didático, aqui investido de psicólogo-terapeuta, busca refletir com eles sobre essas mudanças e problemas (timidez, amor, sofrimento, conflitos sentimentais etc.).

No $2^{\circ}$ grupo o enunciador didático já assume um papel diferente, o de um moralista social - e a imagem criada do destinatário é a de um aprendiz de cidadão. $\mathrm{O}$ enunciador moralista expõe aos aprendizes de cidadão alguns princípios que ele reconhece e considera relevantes para a ética cidadã (responsabilidade ambiental, solidariedade, respeito às diferenças étnicas, crítica ao consumismo, condenação das práticas antiéticas etc.).

No $3^{\circ}$ grupo, o sujeito enunciador assume o papel de um filósofo; expõe e discute questões sobre valores universais construindo uma imagem de destinatário como um discípulo de pensador (conceito de Liberdade, de Justiça, de Humanidade, reflexão sobre o Tempo, a Velhice, a Juventude, a Morte).

Enfim, no $4^{\circ}$ grupo o sujeito enunciador assume o papel de um retor e expõe pontos de vista particulares sobre a arte de falar bem e de escrever bem, construindo uma imagem de destinatário aprendiz de arte retórica e arte oratória. 
Vale ressaltar que nenhum desses tópicos é sumarizado ou explicitado na programação didática, ao contrário dos saberes de conhecimento. Eles surgem implicitados ou acarretados pela escolha temática dos textos e pela estratégia do questionamento nas atividades didáticas. É interessante perceber que as condutas conformes desejadas parecem não poder ser explicitadas como tópicos de ensino e, por isso, devam ser indiretamente ensinadas. Essa atitude decorre, certamente, do fato de que objetivos de ensino como "formação de um espírito crítico" ou "formação de um espírito de cidadania" são vagos e, por isso, recebem variadas interpretações dos autores de livros didáticos.

\subsection{Análise da 'problematização'}

A questão que se coloca para nós neste caso é aquela segundo a qual a linguagem, não podendo ser concebida fora de um quadro interacional, se constitui como um ato de linguagem. Seguindo o pensamento de Michel Meyer (1986), o homem que fala ou escreve tem um problema em mente, ou seja, quando ele empreende uma ação qualquer ele o faz em resposta a um problema que é colocado para ser resolvido. Propor resolver um problema pela linguagem pressupõe que esse problema interessa igualmente ao destinatário, pelo menos é o que o locutor crê. Seguindo ainda Meyer, a expressão de um problema já é, em parte, resposta. É uma resposta parcial, já que se coloca como a primeira etapa em direção à solução que o outro deve trazer. Formular uma questão é já uma maneira de responder ao problema que ela exprime, assim como falar sobre qualquer coisa já é responder à questão de que se trata. Ocorre que, em uma situação natural, a resposta é tão problematológica quanto a pergunta. Em um primeiro momento, ela se refere explicitamente a um problema e, em um segundo momento ela não remete mais ao problema inicial, ela segue problematizando além da solução já contida na questão.

Analisando algumas atividades propostas sobre os universos temáticos que nós descrevemos anteriormente, os enunciadores didáticos formulam questões e, através delas, buscam responder ao problema a que os próprios textos selecionados visam responder. Propõem, assim, um quadro de problematização a que o destinatário deve responder e que supõe, ainda, o seu interesse prévio em fazê-lo. 
$\mathrm{Na}$ análise da problematização podemos distinguir três categorias de perguntas, sendo elas:

1 - perguntas voltadas para a identificação (problematização especular);

2 - perguntas que impõem uma pressuposição e, nesse caso específico, supõem que o destinatário reconhece e valida as condições de verdade do conteúdo pressuposto (problematização validante);

3 - perguntas que orientam para respostas do tipo SIM/NÃO, a escolha sendo já orientada por um princípio de desejabilidade social, ou seja, de fato, não há escolha (problematização normativa).

Nas perguntas do tipo 1, podemos reconhecer uma certa suposição, pelo enunciador didático, de existência de uma continuidade identitária no destinatário. A identidade do destinatário é vista como contínu, negando, assim, a possibilidade de descontinuidade no grupo bem heterogêneo de sujeitos interpretantes empíricos. Ao mesmo tempo, evidencia-se um desejo de aproximação entre os parceiros da relação contratual, já que o enunciador didático assume o papel de psicólogo e delega ao destinatário o papel de paciente de uma relação clínica (enfrentar suas dificuldades da adolescência). A validação da pertinência dessa relação de troca é pressuposta pela instância de produção, mas é bem provável que ela não se realize em situação concreta, pois o interpretante deve aceitar participar da encenação terapêutica com seu professor de português.

Como exemplo, o livro didático apresenta um texto complementar intitulado Aviso, na sua unidade 4, que nos fala sobre o hábito de isolamento, considerado como uma das características da adolescência. $\mathrm{Na}$ tentativa de propor uma interação professor/psicólogo/terapeuta e aluno/paciente em sala de aula, formula-se a seguinte questão:

O que você faz quando está só?

Certamente, esse não é um problema de língua portuguesa, nem de desenvolvimento de competência enciclopédica ou de competência 
procedural, mas de desenvolvimento, se podemos dizer assim, de uma competência axiológica-atitudinal no campo afetivo. Uma tal pergunta supõe uma troca comunicativa bastante íntima entre os parceiros, algo próprio ao ambiente familiar, grupo de amigos íntimos ou, no limite, em relações de terapia. Há certamente variadas possibilidades de respostas sinceras - algumas delas, podemos prever, inadequadas para uma sala de aula. Não seria incomum o aluno responder algo como "quando estou só eu estudo, leio", buscando conformidade com a situação escolar.

O medo também é um tema considerado, neste livro, como um problema recorrente nessa fase dos alunos. Assim, o texto Terror nas sombras, da unidade 10, descreve o sonho medonho de uma criança que se vê quase engolida por uma barata gigante. Depois da leitura do texto, no item reflexão, o autor propõe que os adolescentes falem sobre esse sentimento. Vejamos uma das perguntas formuladas:

Alguma vez você já viven uma situação de pânico ou terror? Conte como foi e o que vocêfer:

Talvez a direção que será dada à problematização inclua um trabalho de desabafo ou de exteriorização de sentimentos de angústia decorrentes da situação de medo e pressão. Já o tema namoro é abordado em três textos do livro. Um deles é Pimpo e Frida, em que o autor conta a estória de dois adolescentes, um menino e uma menina, que depois de tanto brigarem se descobrem apaixonados um pelo outro. Uma das perguntas propostas no item exploração, que sugere um diálogo com os alunos, é:

Você já viveu uma situação semelhante a essa? Como as coisas aconteceram?

Tais perguntas propõem que se responda dentro de uma problematização especular, ou seja, o destinatário precisa se identificar com a figura de adolescente construída na enunciação didática e responder, problematologicamente, dentro desse universo construído.

Ainda no interior desse quadro figurativo terapêutico, outro tipo de questão nos mostra como a estratégia leva o destinatário a validar o quadro figurativo proposto, incluindo afirmações de evidência, ou seja, categóricas, através de efeitos de pressuposição:

Por que ter um namorado é tão importante para as pessoas? 
Nota-se aqui que a resposta problematológica não pode seguir o caminho da refutação da asserção de evidência, já que é preciso, para responder a essa questão, admitir seu pressuposto de que ter um namorado é importante para as pessoas.

Observamos, ainda, que a grande maioria das perguntas do livro se enquadra nos tipos 2 e 3, que tendem à pressuposição, bem como forte orientação das respostas em direção à desejabilidade social, ou seja, respostas normativas. $\mathrm{Na}$ unidade 4, por exemplo, temos o texto complementar "A palavra", de autoria de Rubem Braga. Através dele o sujeito enunciador assume o papel de um retor. Ele nos fala, dentre outros itens, sobre as consequências negativas que podem ser geradas ao proferirmos algumas palavras sem nos darmos conta, e propõe ao aluno (aqui um aprendiz de retórica) uma reflexão sobre como falar bem. A problematização aqui se faz através de perguntas que contêm pressupostos a serem admitidos e não questionados:

Por que é importante utilizar bem as palauras?

A título de exemplo, se a pergunta fosse elaborada sem o pronome interrogativo (É importante utilizar bem as palavras?) ela apagaria a pressuposição e poderia levar o aluno a refletir criticamente sobre se é ou não importante usar bem as palavras (afinal, é possível argumentar contra essa necessidade. Pode-se usar mal as palavras e ser bastante comunicativo).

Vejamos outros exemplos de perguntas extraídas do manual e que explicitam uma pressuposição. Em sua maioria, elas vêm precedidas do pronome Por quê:

(1) Por que a moda nega a identidade das pessoas?

(2) Por que o adolescente, em geral, gosta de roupas com grifes ou etiquetas da moda?

(3) Por que o adolescente, em geral, gosta tanto de falar ao telefone?

(4) Que empregos deixarão de existir com a utilização do computador?

(5) Como você vê a substituição do homem pela máquina? Por quê? 
(6) Que efeitos negativos acarreta o uso do computador no mercado de trabalho?

(7) O que você faz quando está só?

Podemos notar, em cada uma dessas perguntas, um efeito de pressuposição. Em (1) o pressuposto é que a "moda nega a identidade das pessoas". Em (2), que "os adolescentes, em geral, gostam de roupas de grifes". Em (3), que o "adolescente, em geral, gosta de falar ao telefone". Em (4), que "empregos deixarão de existir com a utilização do computador". Em (5), que "o homem será substituído pela máquina". Em (6), que "há efeitos negativos acarretados pelo uso do computador no mercado de trabalho". Em (7), que "o destinatário tem momentos de solidão". A problematização depende da aceitação tácita, pelo destinatário, desses pressupostos.

Em relação ao terceiro tipo de perguntas, aquele que se orienta para respostas do tipo SIM/NÃO, temos alguns exemplos extraídos do livro:

- Você também pensa como Pimpo e Frida, quando dizem que as pessoas normalmente irritam umas às outras porque se gostam?.

- Lemos no texto: "Diz que o homem nasceu livre". Esse direito à liberdade vem sendo respeitado entre os homens?

- Você acha que o irmão do garoto agiu bem ao deixá-lo pular o muro sabendo que havia perigo?

Esse quadro de problematização parece delimitar consideravelmente as possibilidades de problematização nas respostas, e se enquadram dentro de um quadro figurativo da enunciação em que o professor, assumindo papéis comunicacionais de psicólogo, retor, moralista ou filósofo, já traz consigo as respostas aos problemas suscitados pelas questões, respondendo, de fato, às questões e aos problemas que a tradição escolar instituiu como norma para as condutas e para os valores na formação. As perguntas visam mais forçar o reconhecimento de uma conduta aceitável do que produzir uma resposta problematológica crítica. Uma pergunta como "Você acha que é correto jogar o lixo na rua?", não admitiria uma resposta não convencional como "Sim", pois ela se encontra orientada para o "Não". 
Tais exemplos, é claro, mereceriam uma investigação mais sistemática sobre outros livros didáticos e suas estratégias de tematização e de problematização, verificando, por exemplo, como são trabalhadas as diferentes formas de raciocínio lógico e argumentativo, tais como a concessão, a oposição, a restrição, a causa e a consequência, a definição, a comparação etc. Também será importante investigar melhor as estratégias diferenciadas, quando comparamos diferentes manuais didáticos, de desenvolvimento da competência axiológica-atitudinal, já que conseguimos mostrar aqui que os aspectos afetivos e subjetivos constituem, na prática escolar, elementos concretos considerados relevantes na formação dos alunos. Eles estão, portanto, presentes na programação didática, mas são pouco estudados em termos de suas formas de estruturação nos livros didáticos. Outro aspecto que gostaria de ressaltar aqui é a importância de estudar o discurso didático como um ato de comunicação, de modo a identificar seus modos diversos de encenação. Vale destacar ainda que, se o professor deve lecionar e enunciar assumindo papéis ora de psicológico/terapeuta, ora de retor, ora de filósofo ou sociólogo-moralista, seria extremamente valioso reconsiderarmos a relevância, na formação do professor de Português e de Letras, das disciplinas de Psicologia, de Filosofia, de Sociologia e de Política, incluindo, ainda, a de Retórica.

\section{REFERÊNCIAS}

BRASIL. Lei de Diretrizes e Bases da Educação Nacional/ Lei nº 9394, de 20/12/1996. Diário Oficial da União, Brasília, 23 dez. 1996.

CEB. Parecer n. 15/98: diretrizes curriculares nacionais para o Ensino Médio. Relatora: Guiomar Namo de Mello. Diário Oficial da União, Brasília, 25 jun. 1998.

CHARAUDEAU, P. Uma teoria dos sujeitos da linguagem. In: MARI, H. et al. Análise do discurso: fundamentos e práticas. Belo Horizonte: Nad-FaleUFMG, 2001.

EMEDIATO, W. Organização enunciativa e modalização no discurso didático. In: LARA, G. M. P. (Org.). Língua(gem), texto, discurso: entre a reflexão e a prática. Rio de Janeiro: Lucerna; Belo Horizonte: FALE/UFMG, 2006. 
GALATANU, O. Savoirs théoriques et savoirs d'action dans la communication didactique. In: BARBIER, J.-M. (Org.). Savoirs théoriques et savoirs

d'action. Paris: Presses Universitaires de France, 1996.

MEYER, M. De la problématologie. Paris: Pierre Mardaga, 1986.

ROCHEX, J.-Y. Expérience scolaire et travail de subjectivation. In: BARBIER, J.-M. ; GALATANU, O. Action, affects et transformation de soi. Paris: PUF, 1998.

Recebido em 13/09/08. Aprovado em 13/05/09.

Title: Discourse and axiological competence in Portuguese textbooks

Author: Wander Emediato

Abstract: This paper aims at analyzing the presence of didactic strategies used to develop the attitudinal-axiological competence, i. e., affective and subjective aspects, in Portuguese textbooks. The study is based on the semiolinguistics approach to the didactic discourse, and the analytical categories are Thematizations and Problematization as they occur in these textbooks.

Keywords: textbook; discourse; encyclopedic competence; procedural competence; attitudinal competence.

Titre: Discours et expression de compétence axiologique dans des livres didactiques en Langue Portugaise

Auteur: Wander Emediato

Résumé: Cet article cherche à expliquer en se servant des manuels de Langue Portugaise, la présence des stratégies didactiques tournées au développement de la compétence d'attitude axiologique, c'est-à-dire, des aspects affectifs et subjectifs. Il s'agit d'une étude qui, ayant comme base l'approche sémiolinguistique du discours didactique, prend comme catégories d'analyse la Thématisation et la Problématisation selon ce qu'on peut vérifier dans ces livres didactiques.

Mots-clés: discours; livre didactique; compétence encyclopédique; compétence procédurale; compétence d' attitude axiologique.

Título: Discurso y expresión de competencia axiológica en libros didácticos de Lengua Portuguesa

Autor: Wander Emediato

Resumen: Este artículo busca explicar, en los manuales de Lengua Portuguesa, la presencia de estrategias didácticas volcadas para el desarrollo de la competencia axiológica-actitudinal, o sea, de los aspectos afectivos y subjetivos. Se trata de un estudio que, teniendo por base el abordaje semiótico-linguístico del discurso didáctico, toma como categorías de análisis la Tematización y la Problematización conforme se verifican en esos libros didácticos.

EMEDIATO - Discurso e expressão de competência axiológica... 
Palabras-clave: discurso; libro didáctico; competencia enciclopédica; competencia procedimental; competencia axiológica-actitudinal. 